\title{
Antioxidant and Antibacterial Activities of Magnesium Oxide Nanoparticles Prepared using Aqueous Extract of Moringa Oleifera Bark as Green Agents
}

Hanif Amrulloh*, Awalul Fatiqin, Wasinton Simanjuntak, Hapin Afriyani, Annissa Annissa

\begin{tabular}{|c|c|c|c|}
\hline ctober 13,2020 & Revised : January 11, 2021 & Accepted : January 25, 2021 & 021 \\
\hline \multicolumn{4}{|r|}{$\begin{array}{l}\text { t of Moringa } \\
\text { ueous extract } \\
\text { as confirmed } \\
\text { article size of } \\
\text { he MgONPs } \\
\text { coli, and } S \text {. }\end{array}$} \\
\hline
\end{tabular}

Keywords: antibacterial, antioxidant, bark extract, green synthesis, magnesium oxide nanoparticles

\section{INTRODUCTION}

Green method is an experimental procedure that uses extracts from plants as agents to form nanoparticles. This method provides a variety of resources in the process of nanoparticle synthesis [1]-[3]. In addition, there are many other advantages in the use of natural materials in the synthesis of nanoparticles. The use of biodegradable raw materials for the synthesis of nanoparticles has no harmful impact on the environment, leads to a green technology policy, and is first and foremost environmentally friendly. Second, the efficiency of synthesis, which promotes further production through the availability of abundant natural raw materials. Third, the nanoparticles produced are biocompatible in comparison with conventionally seized nanoparticles [4].

Magnesium oxide nanoparticles (MgONPs) are multipurpose metal oxide nanoparticles which have many applications in various fields. MgONPs have been widely used as catalysts [2][5][6] and catalyst supports for various organic reactions [7], adsorbents [8]-[10] and electrochemical biosensors

\section{Copyright Holder:}

(C) Amrulloh, H., Fatiqin, A., Simanjuntak, W., Afriyani, H.,

Annissa, A. (2021)

\section{First Publication Right:}

Journal of Multidisciplinary Applied Natural Science

This Article is Licensed Under:
[11]. In biomedical applications, there are evidence showing MgONPs have antioxidant [12], antibacterial [13]-[15], antifungal [12][16], and anticancer [16] activities.

Moringa Oleifera (M. oleifera) is a multipurpose tropical plant from the Moriceae family which is spread throughout India, Asia, and sub-Saharan Africa [17]. The use of $M$. oleifera extract has been widely used in synthesizing metal nanoparticles and metal oxides. Moringa flower extract can be used to prepare palladium [18], silver [19], and hydroxyapatite [20] nanoparticles. On other hand, Moringa leaf extract is useful to prepare silver [21], zinc oxide [22], titanium oxide [23] and nickel oxide [24] nanoparticles. Phytochemical analysis of water extracts of $M$. oleifera bark shows that Moringa wood bark contains compounds such as alkaloids, phenolic acids, terpenoids, and flavonoids [25]. These compounds play a role in the chelation process and they are able to reduce metal ions to nanoparticles [26].

The effect of $M$. oleifera bark water extract for preparation of MgONPs was examined in this research. This research has been confirmed since the special use of these plant components for nanoparticle preparation is still limited. Characterization of the MgONPs was performed through UV-Vis absorption spectroscopy, X-Ray diffraction (XRD), Electron scanning microscopy (SEM), electron transmission microscopy (TEM), and particle size analyzer (PSA). The bioactivity of MgONPs was subsequently examined as antioxidant and antibacterial agents. 
Table 1. Phytochemicals analysis of M. oleifera bark aqueous extract.

\begin{tabular}{ccc}
\hline Chemical constituents & Testing Methods & M. oleifera bark aqueous extract \\
\hline Alkaloids & Dragendroff's test & + \\
Flavonoids & Shinoda test & + \\
Saponins & Foam test & + \\
Carbohydrate & Anthrone test & - \\
Polyphenols & Puncal-D & - \\
Proteins & Ninhydrin test & - \\
Amino acids & Millon's test & - \\
Phenolics & Ferric chloride test & - \\
Triterpens & Salkowski test & - \\
Anthraquinones & Borntragges test & \\
\hline
\end{tabular}

$+=$ present, $-=$ absence

\section{MATERIALS AND METHODS}

\subsection{Materials}

Fresh M. oleifera bark were collected from the plants that grow naturally around the City of Metro, Lampung, Indonesia during September 2019. Laboratory grade magnesium chloride hexahydrate $\left(\mathrm{MgCl}_{2} \cdot 6 \mathrm{H}_{2} \mathrm{O}\right)$, Folin-Ciocalteu reagents, sodium carbonate $\left(\mathrm{Na}_{2} \mathrm{CO}_{3}\right)$, gallic acid, catechin, aluminum chloride $\left(\mathrm{AlCl}_{3}\right)$, sodium nitrite $\left(\mathrm{NaNO}_{2}\right)$, and sodium hydroxide $(\mathrm{NaOH})$ were purchased from Merck Sigma-Aldrich Reagent Pte, Singapore.

\subsection{Methods}

\subsubsection{Plant extract}

A fresh, M. oleifera sample washed by floating water, dried and then poured into powder and stored at room temperature under direct sunlight. In 100 $\mathrm{mL}$ of distilled water, four grams of M. oleifera bark powder was soaked and heated for 20 minutes at $60^{\circ} \mathrm{C}$. The mixture was then filtered 1 hour with Whatman Filter Paper 1 to isolate the extract from the residue. The mixture was left overnight.

\subsubsection{Phytochemicals analysis}

The aqueous extract was subjected to phytochemical analysis to detect the presence of carbohydrates, amino acids, glycosides, polyphenols, saponins, steroids, flavonoids, tannins, and alkaloids. Total phenolic was estimated using the Follin-Ciocalteu test [27], and the result was expressed in $\mu \mathrm{g} / \mathrm{mg}$ gallic acid equivalent (GAE) unit. Total flavonoid content was determined by the colorimetric $\mathrm{AlCl}_{3}$ method employing catechin as standard and expressed as $\mu \mathrm{g} / \mathrm{mg}$ equivalent of catechin (CE) [28].

\subsubsection{Preparation of $\mathrm{MgO}$ nanoparticles (MgONPS)}

To synthesize MgONPs, $50 \mathrm{~mL}$ of an aqueous extract of M. oleifera barks was mixed with $50 \mathrm{~mL}$ $\mathrm{MgCl}_{2} \cdot 6 \mathrm{H}_{2} \mathrm{O}$ solution $1 \mathrm{mM}$ in a beaker at $90{ }^{\circ} \mathrm{C}$ and stirred at $600 \mathrm{rpm}$. The $1 \mathrm{M} \mathrm{NaOH}$ solution was added drop wise until the color of the mixture faded out and precipitate was formed. The mixture was left for 3 hours to maximize the synthesis process. The MgONPs synthesized was centrifuged at 7,500 rpm at room temperature and re-dispersed in deionized water and methanol $(99 \%)$ to remove biological residues. The process was repeated twice,

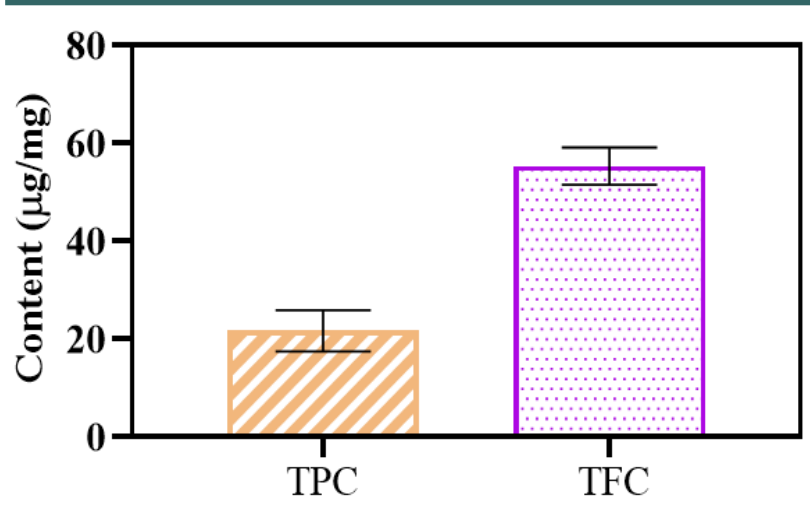

Figure 1. Total phenolic and flavonoid content in M. oleifera bark aqueous extract, Notes: value is mean $\pm \mathrm{SD}$. 
and the solid was dried at $100{ }^{\circ} \mathrm{C}$. The solid was subjected to calcination at $600{ }^{\circ} \mathrm{C}$ for 5 hours was used to optimize the formation of oxides.

\subsubsection{Characterizations of $\mathrm{MgO}$ nanoparticles (MgONPS)}

Several techniques were used to characterize MgONPs. The confirmation of MgONPs synthesis was based on the change in the color of the mixture during the reaction and recorded with UV-Visible spectroscopy (Analytic Jena Specord 200 Plus) by scanning the spectrum in the range of $200-800 \mathrm{~nm}$. The morphology of MgONPs was studied by SEM FEI Inspect-S50. The size and morphology of the MgONPs were investigated by TEM JEOL Jem 1400) and the average particle size by PSA Horiba SZ 100z). The crystal structure of the synthesized MgONPs nanoparticles was confirmed by XRD PANAnalytical Expert Pro.

\subsubsection{Antioxidant activity}

Antioxidant activity of $M$. oleifera bark aqueous extract (BEM) and MgONPs was evaluated through 2,2-diphenyl-1-picrylhydrazyl (DPPH) radical assay in accordance with the procedure described, using ascorbic acid as reference [29]. A DPPH $0.1 \mathrm{mM}$ solution was prepared by dissolving DPPH in ethanol. As much as $1 \mathrm{mg}$ of ascorbic acid was dissolved in $1 \mathrm{~mL}$ of methanol. Dilution was carried out to make a standard solution of ascorbic acid with different concentrations $(50-500 \mu \mathrm{g} / \mu \mathrm{L})$. For each tube containing a standard solution of ascorbic acid $(200 \mu \mathrm{L}), 1 \mathrm{~mL}$ of $0.1 \mathrm{mM}$ DPPH solution was

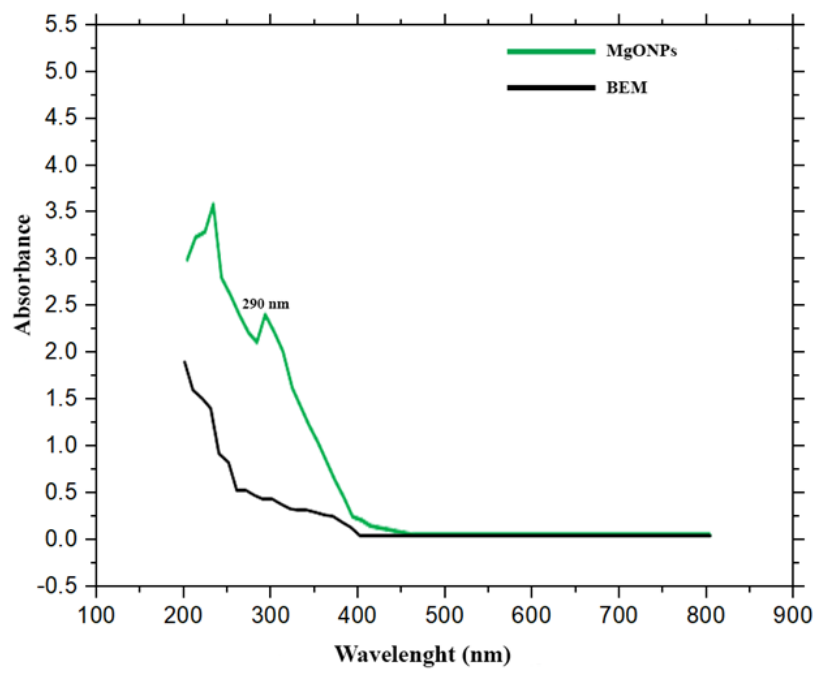

Figure 2. UV-Vis spectrum of M. oleifera aqueous extract and MgONPs. added and followed by the addition of $800 \mu \mathrm{L} 50$ $\mathrm{mM}$ Tris-HCl buffer (pH7.4). The final volume was adjusted to $4 \mathrm{~mL}$ using ethanol. Stock solutions for BEM and MgONPs were prepared by dissolving 1 $\mathrm{mg}$ of each sample in $1 \mathrm{~mL}$ of methanol and dimethylsulfoxide, respectively.

Different aliquots of stock solution $(50-500 \mu \mathrm{g})$ were added to separate tubes, and the final volume was adjusted to $2 \mathrm{~mL}$ using ethanol. A total of $1 \mathrm{~mL}$ of $0.1 \mathrm{mM}$ DPPH solution and $800 \mu \mathrm{L} 50 \mathrm{mM}$ Tris$\mathrm{HCl}$ buffer ( $\mathrm{pH} 7.4)$ was added to each tube. The control was made by mixing $1 \mathrm{~mL}$ DPPH $0.1 \mathrm{mM}$, $800 \mu \mathrm{L} 50 \mathrm{mM}$ Tris-HCl buffer (pH7.4), and $2 \mathrm{~mL}$ ethanol. Absorbance was recorded after incubation for 30 minutes at room temperature, measured by UV-Vis spectrophotometer at $517 \mathrm{~nm}$. The percentage of antioxidant activity (\% Inhibition) was calculated using the following equation:

$(\%$ Inhibition $)=\frac{\text { control absorbance }- \text { sample absorbance }}{\text { control absorbance }} \times 100 \%$

The mean and standard deviation (SD) were calculated based on triplicate measurements by repeating three times.

\subsubsection{Antibacterial activity}

\subsubsection{Microorganism and inoculum preparation}

The antibacterial activity of BEM and MgONPs nanoparticles was evaluated against both grampositive ( $S$. aureus and E. faecalis) and gramnegative (E. coli and $S$. dysenteriae) obtained from the microbiology laboratory of Airlangga University. Bacterial cultures for testing were cultivated on nutrient agar (NA) tilted by selecting a colony from the Mueller-Hinton agar plate (MHA) after 24 hours.

A single bacterial or fungal colony is selected and transferred to the Mueller-Hinton (MHB) broth using a sterilized loop, followed by shaking at 100 rpm at $37{ }^{\circ} \mathrm{C}$ overnight for a normalized population. The optical density of bacterial or fungal suspense was maintained at the standard 0.5 for MacFarland by addition of sterilized MHB for the test of antibacterial and antifungal activities. The inoculum is therefore composed in about 106-107 CFU / mL of several fungi or bacteria. 

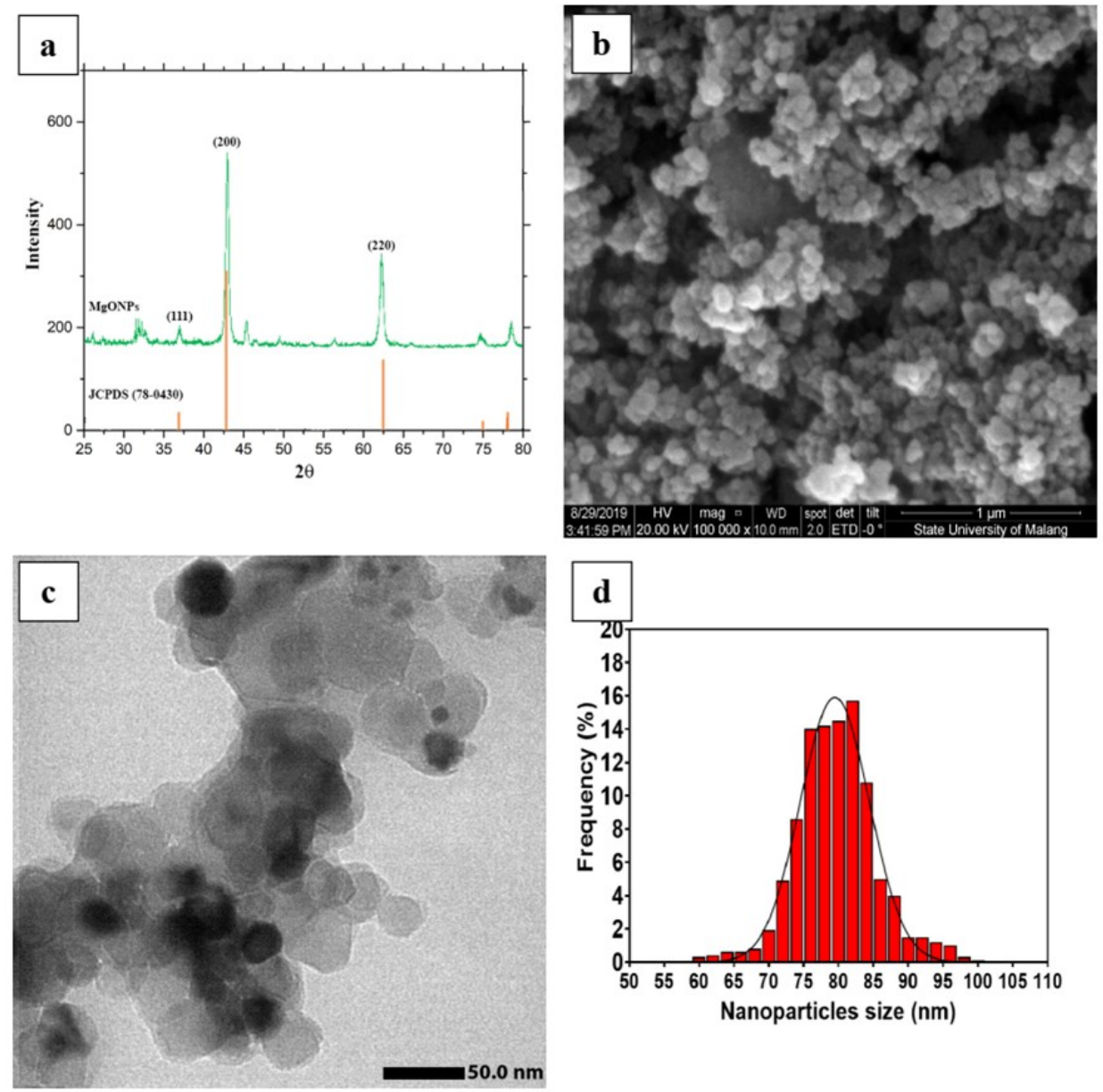

Figure 3. (a) diffraction pattern, (b) SEM image, (c) TEM image and (d) particles size distribution of synthesized MgONPs.

\subsubsection{Minimum inhibition concentration (MIC) determination}

The resazurin microtiter test was used to assess the minimum concentration of inhibition. This approach has been chosen as the easiest and most economical way to simultaneously scan for multiple microorganism isolates and produces satisfactory performance. A $270 \mathrm{mg}$ tablet of resazurin in $40 \mathrm{~mL}$ of sterile distilled water was prepared to dissolve the resazurin solution. The test was conducted in aseptic conditions in 96-well plates. The samples were transferred into the plate well with a volume of $100 \mu \mathrm{L}$ containing $600 \mathrm{mg} / \mathrm{mL}$. Subsequently, the checked sample was applied to all other wells by $50 \mu \mathrm{L}$ of bacterial suspense and diluted severely. Each well was subsequently supplemented with $10 \mu \mathrm{L}$ resazurin solution. The plate was covered with film to avoid dehydration and incubated for 24 hours at $37{ }^{\circ} \mathrm{C}$. The change in color was noticed visually. A change in blue to rose color signaling growth of the cells was considered. In case of a color change, the MIC was registered at the lowest concentration. The mixtures between the sterile distilled water and the dimethylsulfoxide solvents and the nutrient broth were used as adverse controls by Streptomycin (antibacterial) at $0.02 \mu \mathrm{g} /$ $\mu \mathrm{L}$ concentration.

\section{RESULT AND DISCUSSIONS}

\subsection{Phytochemical screening of M. oleifera bark aqueous extract}

Different methods are used to qualitatively test phytochemical compounds contained in M. oleifera (BEM) extracts. The test method used refers to the report Das et al. [29] and the qualitative evaluations of several chemical contents are shown in Table 1.

Table 1 shows BEM extract contains phytochemical compounds such as alkaloids, flavonoids, saponins, and phenolics. These compounds play a role in the chelation process and are able to reduce metal ions to nanoparticles [26].

Total phenolic and flavonoid levels in BEM extract $21.65 \pm 4.25 \mu \mathrm{g} / \mathrm{mg}$ GAE and $55.31 \pm 3.82$ 
$\mu \mathrm{g} / \mathrm{mg}$ CE respectively, as shown in Figure 1 . Extracts of some parts of the plant contain different constituents with distinct functional groups, which can act as reducing or chelating agents in the formation of nanoparticles. Total phenolic and flavonoid levels in bark water extracts are lower than total phenolic and flavonoid levels in water extracts of other $M$. oleifera plants that have been previously reported. Siddhuraju and Becker [30] reported total phenolic content in leaves is $74.30 \pm$ $9.00 \mu \mathrm{g} / \mathrm{mg}$ GAE, while Mohammed and Manan [31] reported total phenolic content in ore is 101.79 $\pm 2.89 \mu \mathrm{g} / \mathrm{mg}$ GAE. The total flavonoid content in leaf water extract was reported by Okumu et al. [32] amounted to $79.13 \pm 13.04(\mu \mathrm{g} / \mathrm{mg} \mathrm{CE})$.

\subsection{Characterization}

\subsubsection{UV-Vis spectroscopy of BEM and MgONPs synthesized}

Synthesis of MgONPs using Moringa aqueous extract followed by a change in color during the synthesis process. The color of the solution changes from clear $\left(\mathrm{MgCl}_{2}\right.$ solution) to dark brown when added with Moringa extract. After addition of $\mathrm{NaOH}$, the color of the solution changes to brighter, indicating the formation of $\mathrm{MgO}$ and $\mathrm{Mg}(\mathrm{OH})_{2}$ complexes in the solution. Adsorption spectrum of MgONPs measured in the range of $200-800 \mathrm{~nm}$. Figure 2 shows the UV spectrum with a sharp peak at around $290 \mathrm{~nm}$, which confirms the formation of $\mathrm{MgO}$ nanoparticles [28]. Besides, the precursor ion $\mathrm{Mg}^{2+}, \mathrm{MgCl}_{2}$ salt does not show a spectrum at the specified wavelength. The existence of a peak of about $280-290 \mathrm{~nm}$ can be attributed to the formation of metal oxide nanoparticles after the addition of plant extracts and $\mathrm{NaOH}$ solution [28].

\subsubsection{Size and morphology of MgONPs synthesized}

In order to correctly assess the atomic position in the lattice structure, a crystalline stage and structure of the synthesized MgONPs were studied using XRD technology. The XRD patterns of MgONPs are shown in Figure 3(a). The MgONPs showed a high intensity peak with two peaks at 42.915 and 62.304 and a low intensity of 31.636 , 74.729 and 78.629. The obtained results have been verified using XRD data (No: 78-0430) from JCPDS. A high purity of synthesized $\mathrm{MgO}$ nanoparticles does not appear as major peaks from
$\mathrm{Mg}$ or other impurities observed on the diffractogram. The average crystalline (D) diameter was calculated with the formula of Scherrer (equation 2) for (200) planes of 20-30 nm.

$D=\frac{K \lambda}{\beta \cos \theta}$

Where $\mathrm{K}$ is a constant dimension depending on the particular geometry of the target, $\lambda$ is the wavelength of $X$-ray radiation, $\beta$ is the full width at half maximum (FWHM) of the significant peaks in radians, and $\theta$ is the Bragg's angle. SEM has been used to carry out morphological tests of MgONPs synthesized with extract. Figure 3(b) shows a micrograph image of the MgONPs. The resulting MgONPs are in the form of spherical particle of 20 to $80 \mathrm{~nm}$.

Figure 3 (c) and (d) shows TEM and PSA of MgONPs prepared. The results of PSA show that the $\mathrm{MgO}$ with particle size in the range of nanometer with relatively narrow distribution was produced. The samples obtained have the particle size in the range of $60-100 \mathrm{~nm}$. The existence of spheres particles with a size ranging from $60-100$ $\mathrm{nm}$ was supported by the results of TEM. Based on these results, $\mathrm{MgO}$ nanoparticles have been successfully produced using aqueous extracts of bark of $M$. oleifera plant, providing an alternative method for synthesizing $\mathrm{MgO}$ nanoparticles. Amrulloh et al. [33] reported the use aqueous extract of Moringa leaves as a green agent in synthesizing MgONPs. The water extract sample of Moringa leaves contains phytochemical compounds such as alkaloids, saponins, carbohydrates, polyphenols, proteins, and amino acids with

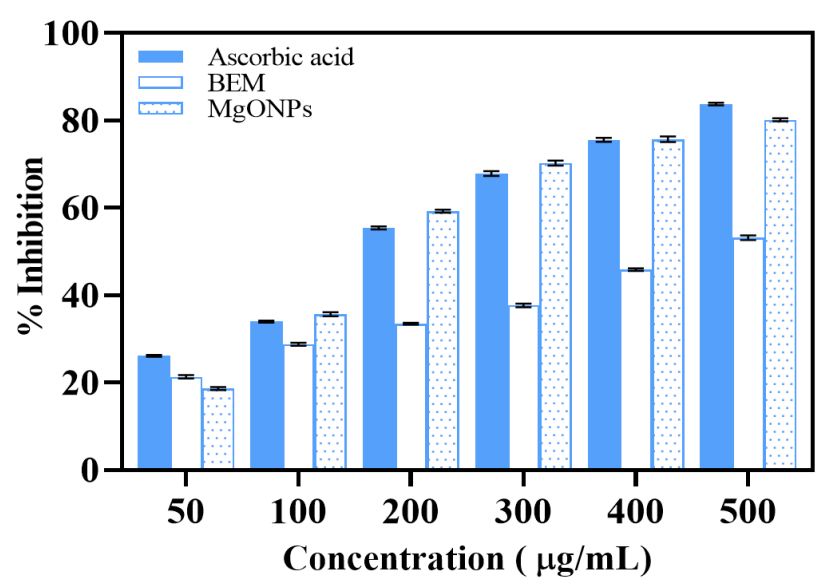

Figure 4. Antioxidant activity of BEM and MgONPs. 


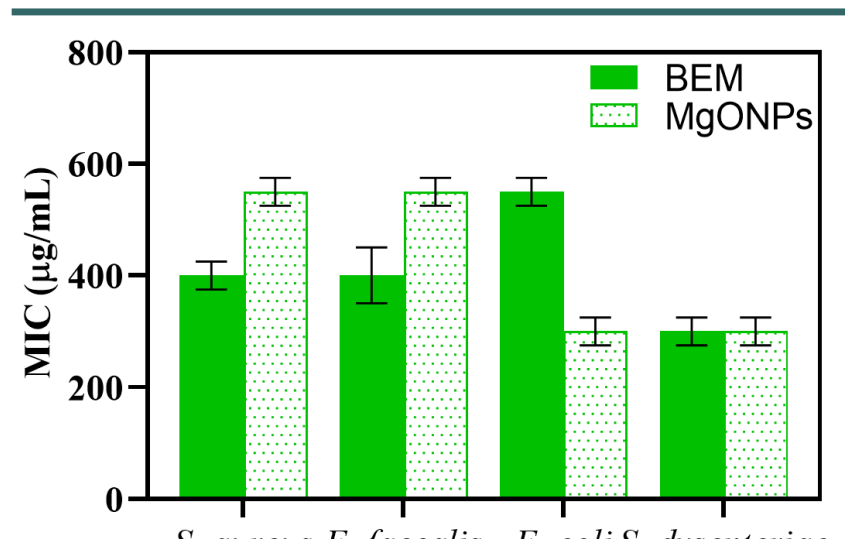

S. aureus E. faecalis E. coli S. dysenteriae

Figure 5. Antibacterial activity of BEM and MgONPs.

phenolics and flavonoids contents of $34.75 \pm 4.03$ $\mu \mathrm{g} / \mathrm{mg}$ GAE and $74.28 \pm 4.82 \mu \mathrm{g} / \mathrm{mg}$ CE, respectively. The structure of the synthesized MgONPs was confirmed by the spherical structure. The average particle size of the synthesized MgONPs measured between 40-70 $\mathrm{nm}$. The MgONPs synthesized from leaf aqueous extract have narrower particle size distribution than that of $\mathrm{MgO}$ produced using bark aqueous extract, which was attributable to the presence of antioxidants-rich compounds (e.g. flavonoids, phenolic acids, reducing sugars, etc.) [34][35]. These biomolecules play a vital role as outstanding bio-reducing and/or bio-capping agents towards generation of the nanoparticles [36].

\subsection{Antioxidant}

The antioxidant activity of BEM and MgONPs was assessed by DPPH test using ascorbic acid as a positive control. The free radical capture activity of DPPH BEM and MgONPs is directly related to their concentration. DPPH is a stable compound and accepts hydrogen or electrons from $\mathrm{BEM}$ or $\mathrm{MgO}$ nanoparticles. This test is often used for the antioxidant activity of compounds present in medicinal plant extracts [37]. The antioxidant activity of MgONPs tends to be higher than that of BEM (Figure 5). Researchers have reported similar observations of antioxidant activity by $\mathrm{MgO}$ [28], $\mathrm{ZnO}$ [38], and $\mathrm{CuO}$ [39] nanoparticles.

\subsection{Antibacterial}

The potential antibacterial activity of BEM and MgONPs was evaluated against gram-positive ( $S$. aureus and E. faecalis) and gram-negative (E. coli and $S$. dysenteriae) bacteria clinically isolated in vitro. MIC values of the presence of BEM against S. aureus, E. faecalis, E. coli, and S. dysenteriae are in the range $300-550 \mathrm{~g} / \mathrm{mL}$ (Figure 5). The antibacterial activity of MgONPs nanoparticles was observed with MIC values $(300-550 \mu \mathrm{g} / \mathrm{mL})$. If the susceptibility between the bacteria tested is compared, $S$. dysenteriae is very susceptible to $\mathrm{BEM}$ and MgONPs compared to other test bacteria. Medicinal plants, including $M$. oleifera, are traditionally used to treat various diseases because of their antibacterial activity [40].

The antibacterial activity of MgONPs against gram-positive and gram-negative test bacteria showed different results. The difference between gram-positive and gram-negative bacteria is mainly in the structure of their cell walls. Gram-positive bacteria have a thick layer of peptidoglycan without an outer membrane and contain teichoic acid. In contrast, gram-negative bacteria have a thin layer of peptidoglycan with an outer membrane that contains lipopolysaccharides. Because of this difference, each type of bacteria shows a different sensitivity [41].

\section{CONCLUSIONS}

Green synthesis of MgONPs that were prepared using $M$. oleifera bark aqueous extract was successfully carried out. The formation of MgONPs in this synthesis was confirmed using UV-Vis absorption. The spherical crystal structure of MgONPs was confirmed by XRD analysis. The average particle size of the synthesized $\mathrm{MgO}$ nanoparticles measured between $60-100 \mathrm{~nm}$ using SEM and TEM images and PSA results. Our study shows that $\mathrm{MgO}$ nanoparticles synthesized exhibit a good antioxidant activity, which is higher than ascorbic acid as a positive standard. We also demonstrated that water extracts of $M$. oleifera bark and MgONPs have medium antibacterial activity against $S$. aureus, E. faecalis, E. coli, and $S$. dysenteriae with MIC values in range of $300-550$ $\mathrm{g} / \mathrm{mL}$.

\section{AUTHOR INFORMATION}

Corresponding Author

Hanif Amrulloh - Department of Mathematic 


\footnotetext{
Education, Institute for Islamic Studies Ma'arif

NU (IAIMNU), Metro-34111 (Indonesia) ;

(D) orcid.org/0000-0001-7458-9258

Email:

amrulloh.hanif@iaimnumetrolampung.ac.id
}

Authors

Awalul Fatiqin - Department of Biology, Islamic State University Raden Fatah, Palembang -30126 (Indonesia);

orcid.org/0000-0001-7799-2835

Wasinton Simanjuntak - Department of Chemistry, Lampung University, Bandar Lampung- 3514 (Indonesia);

orcid.org/0000-0001-8152-5084

Hapin Afriyani - Department of Chemistry, Lampung University, Bandar Lampung- 3514 (Indonesia);

orcid.org/0000-0002-6092-127X

Annissa Annissa - Department of Public Health, Faletehan University, Serang-42161 (Indonesia);

\section{ACKNOWLEDGEMENT}

This research supported by the Ministry of Religious Affairs Republic Indonesia through collaboration research BOPTN UIN Raden Fatah Palembang No: B-383/Un.09/PP.06/05/2019. Furthermore, acknowledgment also expressed for the full support from Laboratorium Sentral Mineral \& Material Maju Universitas Negeri Malang, Direktorat Riset \& Pengabdian Masyarakat Universitas Indonesia, and Laboratorium TEM Jurusan Kimia Universitas Gajah Mada for technical contributions on the research projects.

\section{REFERENCES}

[1] L. Katata-Seru, T. Moremedi, O. S. Aremu, and I. Bahadur. (2018). "Green synthesis of iron nanoparticles using Moringa oleifera extracts and their applications: Removal of nitrate from water and antibacterial activity against Escherichia coli”. Journal of Molecular Liquids. 256 : 296-304. 10.1016/ j.molliq.2017.11.093.

[2] Y. Abdallah, S. O. Ogunyemi, A. Abdelazez, M. Zhang, X. Hong, E. Ibrahim, A. Hossain,
H. Fouad, B. Li, and J. Chen. (2019). "The Green Synthesis of MgO Nano-Flowers Using Rosmarinus officinalis L. (Rosemary) and the Antibacterial Activities against Xanthomonas oryzae pv. oryzae". BioMed Research International. $\mathbf{2 0 1 9} \quad$ : 5620989. 10.1155/2019/5620989.

[3] G. Sharma, R. Soni, and N. D. Jasuja. (2017). "Phytoassisted synthesis of magnesium oxide nanoparticles with Swertia chirayaita". Journal of Taibah University for Science. 11 (3): 471-477. 10.1016/j.jtusci.2016.09.004.

[4] G. Pal, P. Rai, and A. Pandey. (2019). in "A. K. Shukla and I. Siavash (ed) Green Synthesis, Characterization and Applications of Nanoparticles". Elsevier Inc, Amsterdam. 10.1016/C2017-0-02526-0.

[5] B. Wang, X. Xiong, H. Ren, and Z. Huang. (2017). "Preparation of MgO nanocrystals and catalytic mechanism on phenol ozonation". RSC Advances. 7 (69): 43464-43473. 10.1039/c7ra07553g.

[6] M. B. Gawande, P. S. Branco, K. Parghi, J. J. Shrikhande, R. K. Pandey, C. A. A. Ghumman, N. Bundaleski, O. M. N. D. Teodorod, and R. V. Jayaram. (2011). "Synthesis and characterization of versatile $\mathrm{MgO}-\mathrm{ZrO}_{2}$ mixed metal oxide nanoparticles and their applications," Catalysis Science \& Technology. 1 (9): 1653-1664. 10.1039/ c1cy00259g.

[7] J. Chen, M. Zhang, C. Pang, F. Xiang, M. Zhu, X. Ma, G. Chang, and W. Yin. (2020). "Hydrophilic $\mathrm{Pd} / \mathrm{MgO}$ Nanosystem for the Highly Efficient Aqueous-Phase Catalysis of Suzuki-Miyaura Reactions". Industrial \& Engineering Chemistry Research. 59 (1): 8187. 10.1021/acs.iecr.9b05248.

[8] V. Srivastava, Y. C. Sharma, and M. Sillanpää. (2015). "Green synthesis of magnesium oxide nanoflower and its application for the removal of divalent metallic species from synthetic wastewater". Ceramics International. 41 (5): 6702-6709. 10.1016/j.ceramint.2015.01.112.

[9] Z. Camtakan, S. Erenturk, and S. Yusan. (2012). "Magnesium oxide nanoparticles: Preparation, characterization, and uranium sorption properties," Environmental Progress 
\& Sustainable Energy. 31 (4): 536-543. 10.1002/ep.10575.

[10] A. A. Pilarska, Ł. Klapiszewski, and T. Jesionowski. (2017). "Recent development in the synthesis, modification and application of $\mathrm{Mg}(\mathrm{OH})_{2}$ and $\mathrm{MgO}$ : A review". Powder Technology. 319 : 373-407. 10.1016/ j.powtec.2017.07.009.

[11] H. R. Raveesha, S.Nayana, D. R. Vasudha, J. P. S. Begum, S. Pratibha, C. R. Ravikumara, N. Dhananjaya. (2019). "The electrochemical behavior, antifungal and cytotoxic activities of phytofabricated $\mathrm{MgO}$ nanoparticles using Withania somnifera leaf extract". Journal of Science: Advanced Materials and Devices. 4 (1): 57-65. 10.1016/j.jsamd.2019.01.003.

[12] K. Kandiah, T. Jeevanantham, and B. Ramasamy. (2019). "Reliability of antioxidant potential and in vivo compatibility with extremophilic actinobacterial-mediated magnesium oxide nanoparticle synthesis". Artificial Cells, Nanomedicine, and Biotechnology. $47 \quad$ (1): $\quad 862-872$. 10.1080/21691401.2019.1580287.

[13] A. M. Azzam, M. A. Shenashen, B. B. Mostafa, W. A. Kandeel, and S. A. El-Safty. (2019). "Antibacterial Activity of Magnesium Oxide Nano-hexagonal Sheets for Wastewater Remediation". Environmental Progress \& Sustainable Energy. 38 (s1): S260-S266. 10.1002/ep.12999.

[14] M. Suma, G. N. Sushma, M. Zikriya, and Y. F. Nadaf. (2020). "Photocatalytic and antibacterial approach of green synthesised $\mathrm{MgO}$ nanoparticles". 3rd International Conference on Condensed Matter and Applied Physics. $\mathbf{2 2 2 0}$ : 020072. 10.1063/5.0002154.

[15] S. C. De La Rosa-García, P. Martínez-Torres, S. Gómez-Cornelio, M. A. Corral-Aguado, P. Quintana, and N. M. Gómez-Ortíz. (2018). "Antifungal activity of $\mathrm{ZnO}$ and $\mathrm{MgO}$ nanomaterials and their mixtures against colletotrichum gloeosporioides strains from tropical fruit". Journal of Nanomaterials. 2018. $10.1155 / 2018 / 3498527$.

[16] B. Mangalampalli, N. Dumala, and P. Grover. (2019). "Toxicity assessment of magnesium oxide nano and microparticles on cancer and non-cancer cell lines". The Nucleus. 62 (3): 227-241. 10.1007/s13237-019-00298-9.

[17] A. F. A. Razis, M. D. Ibrahim, and S. B. Kntayya. (2014). "Health benefits of Moringa oleifera". Asian Pacific Journal of Cancer Prevention. 15 (20): 8571-8576. 10.7314/ APJCP.2014.15.20.8571.

[18] K. Anand, C. Tiloke, A. Phulukdaree, B. Ranjan, A. Chuturgoon, S. Singh, R. M. Gengan. (2016). "Biosynthesis of palladium nanoparticles by using Moringa oleifera flower extract and their catalytic and biological properties". Journal of Photochemistry and Photobiology B: Biology. 165 : 87-95. 10.1016/ j.jphotobiol.2016.09.039.

[19] M. R. Bindhu, M. Umadevi, G. A. Esmail, N. A. Al-Dhabi, and M. V. Arasu. (2020). "Green synthesis and characterization of silver nanoparticles from Moringa oleifera flower and assessment of antimicrobial and sensing properties". Journal of Photochemistry and Photobiology B: Biology. 205. 10.1016/j.jphotobiol.2020.111836.

[20] M. Sundrarajan, S. Jegatheeswaran, S. Selvam, N. Sanjeevi, and M. Balaji. (2015). "The ionic liquid assisted green synthesis of hydroxyapatite nanoplates by Moringa oleifera flower extract: A biomimetic approach". Materials \& Design. 88 : 11831190. 10.1016/j.matdes.2015.09.051.

[21] J. S. Moodley, S. B. N. Krishna, K. Pillay, Sershen, and P. Govender. (2018). "Green synthesis of silver nanoparticles from Moringa oleifera leaf extracts and its antimicrobial potential". Advances in Natural Sciences: Nanoscience and Nanotechnology. 9 (1): 015011. 10.1088/2043-6254/aaabb2.

[22] K. Elumalai, S. Velmurugan, S. Ravi, V. Kathiravan, and S. Ashokkumar. (2015). "Green synthesis of zinc oxide nanoparticles using Moringa oleifera leaf extract and evaluation of its antimicrobial activity". Spectrochimica Acta Part A: Molecular and Biomolecular Spectroscopy. 143 : 158-164. 10.1016/j.saa.2015.02.011.

[23] V. Sivaranjani and P. Philominathan. (2016). "Synthesize of Titanium dioxide nanoparticles using Moringa oleifera leaves and evaluation 
of wound healing activity". Wound Medicine. 12 : 1-5. 10.1016/j.wndm.2015.11.002.

[24] A. A. Ezhilarasi, J. J. Vijaya, K. Kaviyarasu, M. Maaza, A. Ayeshamariam, and L. J. Kennedy. (2016). "Green synthesis of NiO nanoparticles using Moringa oleifera extract and their biomedical applications: Cytotoxicity effect of nanoparticles against HT-29 cancer cells". Journal of Photochemistry and Photobiology B: Biology. 164 : $\quad 352-360 . \quad 10.1016 /$ j.jphotobiol.2016.10.003.

[25] H. P. N. Sholapur and B. M. Patil. (2013). "Pharmacognostic and phytochemical investigations on the bark of Moringa oleifera Lam.”. Indian Journal of Natural Products and Resources. 4 (1): 96-101.

[26] C. Tiloke and A. A. Chuturgoon. In "V. C. Kalia and A. K. Saini (eds) Engineering for Bioactive Compounds: Strategies and Processes". Springer Singapore, Singapore.

[27] R. Magesh, R. M. Poorani, V. Karthikeyan, K. Sivakumar, and C. Mohanapriya. (2015). "Proportionate phytochemical screening and assessment of antioxidant potency on selected species of lamiaceae family". International Journal of Pharmacognosy and Phytochemical Research. 7 (5): 1066-1072.

[28] B. Das, S. Moumita, S. Ghosh, M. I. Khan, D. Indira, R. Jayabalan, S. K.Tripathy, A. Mishra, and P. Balasubramanian. (2018). "Biosynthesis of magnesium oxide $(\mathrm{MgO})$ nanoflakes by using leaf extract of Bauhinia purpurea and evaluation of its antibacterial property against Staphylococcus aureus". Materials Science and Engineering: C. 91 : 436-444. 10.1016/j.msec.2018.05.059.

[29] P. E. Das, A. F. Majdalawieh, I. A. AbuYousef, S. Narasimhan, and P. Poltronieri. (2020). "Use of a hydroalcoholic extract of moringa oleifera leaves for the green synthesis of bismuth nanoparticles and evaluation of their anti-microbial and antioxidant activities," Materials. 13 (4). 10.3390/ma13040876.

[30] P. Siddhuraju and K. Becker. (2003). "Antioxidant properties of various solvent extracts of total phenolic constituents from three different agroclimatic origins of drumstick tree (Moringa oleifera Lam.) leaves". Journal of Agricultural and Food Chemistry. 51 (8): 2144-2155. 10.1021/ if020444+.

[31] S. Mohammed and F. A. Manan. (2015). "Analysis of total phenolics, tannins and flavonoids from Moringa oleifera seed extract". Journal of Chemical and Pharmaceutical Research. 7 (1): 132-135.

[32] M. O. Okumu, J. M. Mbaria, L. W. Kanja, D. W. Gakuya, S. G. Kiama, and F. O. Ochola. (2016). "Phytochemical profile and antioxidant capacity of leaves of Moringa oleifera ( Lam ) extracted using different solvent systems". Journal of Pharmacognosy and Phytochemistry. 5 (4): 302-308.

[33] H. Amrulloh, A. Fatiqin, W. Simanjuntak, H. Afriyani, and A. Annissa. (2021). "Bioactivities of Nano-scale Magnesium Oxide Prepared Using Aqueous Extract of Moringa Oleifera Leaves as Green Agent". Advances in Natural Sciences: Nanoscience and Nanotechnology.

[34] M. Hariram, S. Vivekanandhan, V. Ganesan, S. Muthuramkumar, A. Rodriguez-uribe, A. K. Mohanty, M. Misra. (2019). "Tecoma stans flower extract assisted biogenic synthesis of functional Ag-Talc nanostructures for antimicrobial applications". Bioresource Technology Reports. 7. 10.1016/ j.biteb.2019.100298.

[35] D. T. C. Nguyen, H. H. Dang, D. V. N. Vo, L. G. Bach, T. D. Nguyen, and T. Van Tran. (2021). "Biogenic synthesis of $\mathrm{MgO}$ nanoparticles from different extracts (flower, bark, leaf) of Tecoma stans (L.) and their utilization in selected organic dyes treatment". Journal of Hazardous Materials. 404. 10.1016/j.jhazmat.2020.124146.

[36] E. R. Essien, V. N. Atasie, E. U. Udobang, and G. Umanu. (2019). "Preparation of monodispersed and cytotoxic silver nanoparticles using Launaea taraxacifolia leaf extract". Journal of Nanostructure in Chemistry. 9 (4): 259-268. 10.1007/s40097019-00316-x.

[37] S. Dewanjee, M. Gangopadhyay, N. Bhattacharya, R. Khanra, and T. K. Dua. (2015). "Bioautography and its scope in the 
field of natural product chemistry". Journal of

Pharmaceutical Analysis. 5 (2): 75-84.

10.1016/j.jpha.2014.06.002.

[38] T. Safawo, B. V. Sandeep, S. Pola, and A. Tadesse. (2018). "Synthesis and characterization of zinc oxide nanoparticles using tuber extract of anchote (Coccinia abyssinica (Lam.) Cong.) for antimicrobial and antioxidant activity assessment". OpenNano. 3 : $56-63 . \quad \underline{10.1016 /}$ j.onano.2018.08.001.

[39] R. Dobrucka. (2018). “Antioxidant and Catalytic Activity of Biosynthesized $\mathrm{CuO}$ Nanoparticles Using Extract of Galeopsidis herba". Jounal of Inorganic and Organometallic Polymers and Materials. 28 (3): 812-819. 10.1007/s10904-017-0750-2.

[40] K. Z. Khor, V. Lim, E. J. Moses, and N. Abdul Samad. (2018). "The in Vitro and in Vivo Anticancer Properties of Moringa oleifera". Evidence-based Complementary and Alternative Medicine. 2018. 10.1155/2018/1071243.

[41] N. Y. T. Nguyen, N. Grelling, C. L. Wetteland, R. Rosario, and H. Liu. (2018). "Antimicrobial Activities and Mechanisms of Magnesium Oxide Nanoparticles (nMgO) against Pathogenic Bacteria, Yeasts, and Biofilms". Scientific Reports. 8 (1). 10.1038/ s41598-018-34567-5. 